\title{
RP-HPLC METHOD FOR SIMULTANEOUS ESTIMATION OF FINASTERIDE AND TAMSULOSIN IN TABLET FORMULATIONS
}

\author{
Ashu Mittal ${ }^{1}$, Shikha Parmar $^{2}$ Syed Sarim Imam ${ }^{3}$, Sadaf J. Gilani ${ }^{1}$, Mohd Aqil ${ }^{3}$
}

1.KIET School of Pharmacy, Ghaziabad 201206, UP, India

2.Faculty of Pharmacy, HRGI, Ghaziabad 201206, UP, India

3.Faculty of Pharmacy, Jamia Hamdard, New Delhi 110062, India

Submitted: $28-07-2014$

Revised: $10-10-2014$

Accepted: 20-11-2014

*Corresponding author Ashu Mittal

Email:

ashumittal1973@gmail.com

\section{INTRODUCTION}

During the drug development process, liquid chromatographic methods are used to determine the quality of the drug substance (active pharmaceutical ingredient) and drug product. RP-Liquid chromatography is the most accepted analytical technique in the pharmaceutical industry. Finasteride (Figure 1) is an antiandrogen which acts by inhibiting 5alpha reductase, the enzyme that converts testosterone to dihydrotestosterone. In high dose, it is used to treat prostate cancer, while in low doses used in benign prostatic hyperplasia.

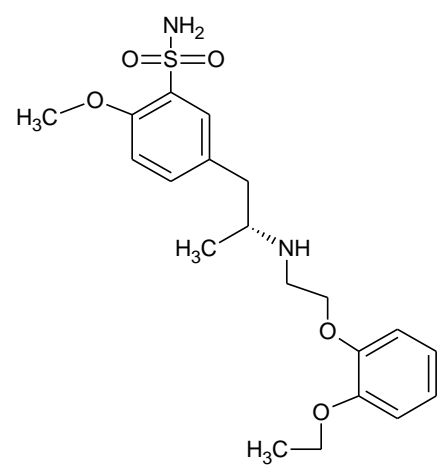

Figure 1. Chemical structure of tamsulosin.
It is chemically known as N-(1,1dimethylethyl)-3-oxo-(5alpha,17beta)-4- azaandrost- 1- ene-17- carboxamide. (Thimmaraju et al., 2011). Tamsulosin hydrochloride (Figure 2) is an antagonist of alpha1 $\mathrm{A}$ adrenoceptors in the prostate and chemically described as $(-)-(\mathrm{R})-$ $5-[2-[[2-(\mathrm{o}-$ Ethoxyphenoxy $)$ ethyl $]$ amino] propyl] -2-methoxybenzenesulfonamide, monohydrochloride. It is used to reduce urinary obstruction and relieve the symptoms associated with symptomatic benign prostatic hyperplasia. Both drugs in combination used in the treatment of benign prostatic hyperplasia, enlarged postate (Merck Index., 2006; Patel et al., 2010; Thimmaraju et al., 2011 and Basavaiah et al., 2007).<smiles>CC(C)(C)NC(=O)C1CCC2[C@@H]3CC[C@@H]4NC(=O)C=C[C@]4(C)C3CCC12C</smiles>

Figure 2. Chemical structure of finasteride. 
As per prior literature survey, it was found that there are few analytical methods are available for quantitation of finasteride alone as well as in biological fluid by various analytical technique such as polarographic analysis (Amer., 2005), HPLC in biological fluid (Constanzer et al., 2001: Carlucci et al., 1997), HPLC in formulation (Patel et al., 2010; Thimmaraju et al., 2011 and Syed et al., 2001) and LC-MS (Constanzer et al., 1994; Guo et al., 2007; Xiaohong et al., 2008 and Ptacek et al., 2000). There are few methods reported for tamsulosin estimation alone as well as in biological fluid are HPLC (Soeishi et al., 1990), LC-MS (Matsushima et al., 1997; Rahkonen et al., 2007; Din et al., 2002 and Ramakrishna et al., 2005) in pharmaceuticals formulation. However there are very few HPLC methods are reported for simultaneous estimation of TAM and FIN in combined pharmaceutical formulations (Patel et al., 2010; Thimmaraju et al., 2011). However, the limited number of HPLC methods that are available for regular routine analysis of TAM and FIN in pharmaceutical formulations (laboratory developed tablet dosage form ) employ the use of high cost solvents that are found to be highly complex and are associated with increasing numbers of process variables, which makes them less acceptable for routine analysis. This paper reports a rapid and sensitive HPLC determination method with UV detection, useful for routine quality control for simultaneous estimation of both drugs in the combined dosage form. The method requires strong optimization process like mobile phase composition, $\mathrm{pH}$ of mobile phase, and flow rate. Therefore an attempt was made to develop and optimize new solvent system for simultaneous estimation of FIN and TAM in bulk as well as in tablet formulation. The developed method was validated in accordance with the ICH guidelines (ICH,Q2R1 2005).

\section{MATERIAL AND METHODS Chemicals and reagents}

TAM and FIN were donation from Ranbaxy limited, India. Methanol (HPLC grade), disodium hydrogen phosphate and acetic acid glacial (AR Grade) were purchased from E-Merck Ltd. (Mumbai, India). Ultrapurified HPLC grade water was obtained from
Milli-Q ${ }^{\circledR}$ system (Millipore, Milford, MA, USA) water purification unit. Mobile phase was filtered using $0.45 \mu$ nylon filters made by Millipore (USA) and was sonicated using sonicator.

\section{HPLC and chromatographic conditions}

HPLC system (Waters) was used for the estimation drugs. The system was equipped by high pressure pump and a rheodyne injection valve with a $20 \mu \mathrm{L}$ loop used for sample injection. A Hypersil ODS C-18 column $(250 * 4.6 \mathrm{~mm}$, i.d., $5 \mu \mathrm{M}$ particle size) was used in this research. The mobile phase was composed of methanol: $0.03 \mathrm{mM}$ phosphate buffer $(\mathrm{pH}$ $3.5)$, in the ratio of $(70: 30 \mathrm{v} / \mathrm{v})$ and flow rate was adjusted $1 \mathrm{~mL} / \mathrm{min}$ at room temperature $\left(25 \pm 2^{\circ} \mathrm{C}\right)$. The mobile phase was prepared daily and degassed by ultrasonication before use.

\section{Preparation of standard drug solutions}

The standard solutions of both drugs were prepared by dissolving $25 \mathrm{mg}$ of finasteride and $10 \mathrm{mg}$ of tamsulosin in $10 \mathrm{~mL}$ of methanol in volumetric flask. The prepared solution was filtered and further diluted to make series concentration in linearity range of $4-40 \mu \mathrm{g} / \mathrm{mL}$ for TAM and $10-80 \mu \mathrm{g} / \mathrm{mL}$ for FIN.

\section{Assay of tablet}

The analyses of in house developed formulations were performed by weighing 20 tablets. The tablets were powdered and appropriate portion of this powder, equivalent to $25 \mathrm{mg}$ of finasteride and $10 \mathrm{mg}$ of tamsulosin were weighed and transferred in a $10 \mathrm{~mL}$ volumetric flask and further dissolved in methanol. This solution was sonicated for $10 \mathrm{~min}$ to dissolve entire active from the tablet. Once the time had elapsed and the volumetric flask reached the environmental temperature $\left(25^{\circ} \mathrm{C}\right)$. The solution was filtered through a $0.45 \mu \mathrm{M}$ filter to ensure the absence of particulate matter. The filtered solution was appropriately diluted further to get the desired concentration for the estimation.

\section{Method validation}

The developed method was validated for parameters viz. linearity range, precision, accuracy, specificity, selectivity, limit of quantitation (LOQ), and limit of detection (LOD), robustness and solution stability. 
Linearity range: The linearity of an analytical method is its ability of an analytical method to show a directly proportional relationship of a quantitative response to a specific concentration of an analyte within a given specified range of concentrations. Accurately measured aliquots of working standard solutions of TAM and FIN were diluted with methanol to obtain final concentrations of TAM $(4-40 \mu \mathrm{g} / \mathrm{mL})$ and FIN $(10-80 \mu \mathrm{g} / \mathrm{mL})$. Calibration curves were constructed by plotting peak areas $v s$. concentrations, and regression equations were calculated.

System suitability: System suitability parameters were measured so as to verify the system performance. It was determined on six replicate injections of standard solutions. All important characteristics including capacity factor, peak resolution, and theoretical plate number were measured.

Accuracy: The accuracy was determined by standard additions method at three different levels, i.e. by multiple level recovery studies. The recovery studies were performed at 50\%, $100 \%, 150 \%$ level from initial level. It was done by injection of solution $(n=5)$ of known concentrations of drugs that had been prepared from stock solutions. Percent recovered were calculated for drug using regression equation.

Precision: The precision study was assessed by evaluating chromatographic responses of repeated injections $(n=5)$ of known concentrations of both TAM and FIN over the concentration ranges studied. The intra-day precision refers to the use of analytical procedure within a laboratory over a short period of time using the same operator with same equipment. The inter-day precision involves estimation of variations in analysis when a method is used within a laboratory on different days, by same analysts. Repeatability is reported in terms of relative standard deviation (\%RSD).

Specifity and Selectivity : It is used to check the proposed method of a combination tablet of TAM and FIN that contain commonly occurring excipient present formulations. The comparison of chromatogram of sample with chromatograms of the standard solution was done to check the variation in the retention time along with percentage recovery.
Limit of Quantitation (LOQ) and Limit of Detection (LOD) : It was calculated by method which was based on the standard deviation (S.D) of the response and slope (S) of the calibration curve. LOD and LOQ were determined as follows.

LOD $=3.3 \mathrm{X}$ Standard deviation of $\mathrm{y}$ intercept / Slope of calibration curve

$\mathrm{LOQ}=10 \mathrm{X}$ Standard deviation of $\mathrm{y}$ intercept / Slope of calibration curve

Robustness: The robustness of an analytical method refers to its capability to remain unaffected by small and deliberate variations in experimental condition. The conditions studied were flow rate (altered by \pm $0.2 \mathrm{~mL} / \mathrm{min}$ ), mobile phase composition (methanol $\pm 5 \%$ ), and buffer $\mathrm{pH}$ (altered by \pm $0.2)$.

Stability: The stability of drug solution was determined using the samples for shortterm stability by keeping at room temperature for $12 \mathrm{~h}$ and then analyzing. The long-term stability was determined by storing at $4^{\circ} \mathrm{C}$ for 30 days.

\section{RESULTS AND DISCUSSION}

In this work a simple, sensitive and valid HPLC method has been developed for simultaneous estimation of FIN and TAM using RP-HPLC. There are various combination of mobile phases were initially attempted to elute simultaneously both components and to achieve sharp peaks. Most of the time FIN and TAM eluted with very small value of retention factor $(\mathrm{k})$ associated with long retention time. The capacity factor $\left(K_{-}\right)$of both the drug was found to be optimum according to the studied parameters. The capacity factor obtained is within the accepted values, above 2 for the first peak and less than 10 for the last peak. During method development preference was given to methanol as choice of solvent. The various mobile phase compositions have been tried i.e. with methanol: water, methanol: formic acid $0.1 \%$, methanol: sulphate buffer, however the result showed that both compounds FIN and TAM cannot be properly separated. The selected mobile phase composition consisted of methanol: $0.03 \mathrm{mM}$ phosphate buffer ( $\mathrm{pH}-3.5)$, in the ratio of $70: 30 \mathrm{v} / \mathrm{v}$. Retention time of FIN and TAM was 3.52 and $8.03 \mathrm{~min}$ (Figure 3), respectively. 


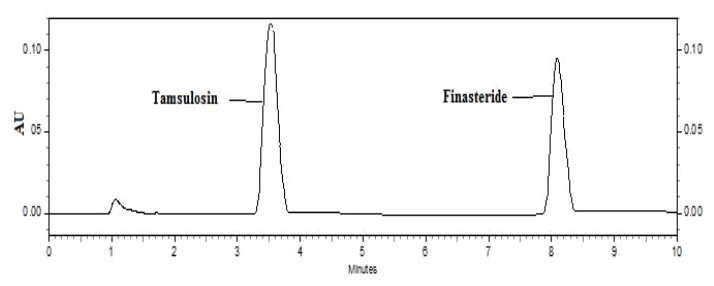

Figure 3. Chromatograms of tamsulosin and finasteride reference sample.

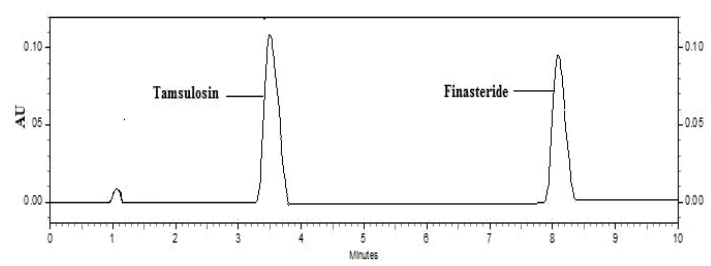

Figure 4. Chromatograms of tamsulosin and finasteride test sample.

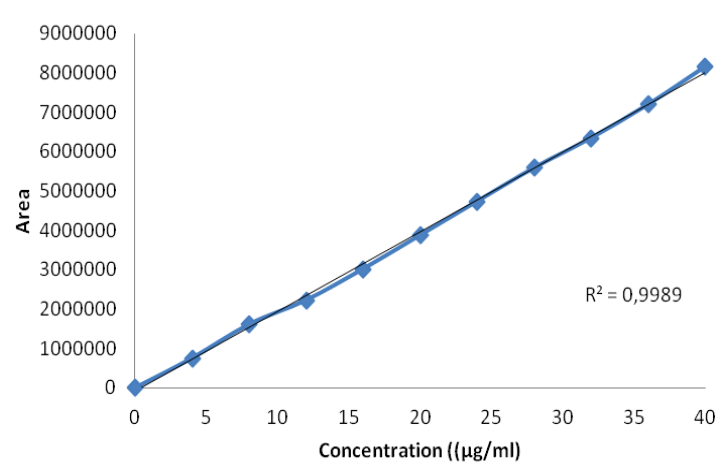

Figure 5. Linearity curve of Tamsulosin.

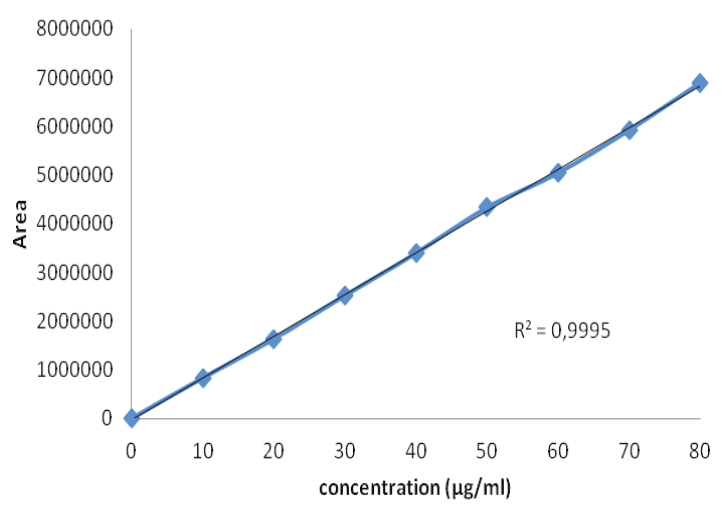

Figure 6. Linearity curve of Finasteride

Linearity: The linearity range for TAM and FIN were $4-40 \mu \mathrm{g} / \mathrm{mL}$ and $10-80 \mu \mathrm{g} / \mathrm{mL}$, respectively (Figure 5 and 6 ). The correlation coefficient values were found to be greater than
0.99 for both the drugs. The relevant equations for these are $\mathrm{Y}=71217 \mathrm{x}+12015$ and $\mathrm{Y}=$ 66761x - 8554.9 for TAM and FIN (Table I).

System suitability: The $\%$ RSD of peak area and retention time for both drugs was within $2 \%$ indicating that the method was suitable for analysis the drugs (Table II). The efficiencies of the column as expressed by number of theoretical plates for TAM and FIN were $6844 \pm 2 \%$ and $11577 \pm 1.96$, respectively. The capacity factor and tailing factor for TAM and FIN were 2.1, 6.3, 0.44 and 0.82 respectively. Therefore the method complied with limits stipulated by USP for system suitability for the peaks.

Accuracy (Recovery studies): The recoveries of the drugs were determined by standard addition method. The result suggests that, the method can be considered accurate, as the $\% \mathrm{RSD}$ of all the determinants were to be $<2 \%$ which indicated that the method was accurate and also there was no interference of the excipients present in tablets (Table III).

Precision: In inter-day precision studies expressed by \% RSD value of TAM and FIN were between 0.278-0.750 and 0.563-0.874, respectively. The result of intra-day precision study expressed as \%RSD value were in range of $0.316-0.743$ for TAM and $0.740-0.933$ for FIN (Table 4). The \% RSD results of inter-day precision and intra-day precision for both drugs were within $2.0 \%$ limit, which confirming good precision of developed analytical method.

Specificity and selectivity: Specificity and selectivity were studied for presence of interfering endogenous components. The results indicated that there were not much variations in retention time of pure drug and tablet formulation. The result showed that none of impurities were interfering in the assay. According to the chromatogram (Figure 4), the both peaks TAM, FIN were free from interference of formulation excipients, the solvent system and each other. This indicated the selected method was specific for simultaneously determination TAM and FIN.

Limit of Detection and Limit of Quantification: The LOD and LOQ of TAM were 1.13 and $3.43 \mu \mathrm{g} / \mathrm{mL}$, respectively, while those of FIN were 1.37 and $4.21 \mu \mathrm{g} / \mathrm{mL}$. 
Table I. Analytical parameters of Tamsulosin and Finasteride

\begin{tabular}{lll}
\hline Regression parameter & Tamsulosin & Finasteride \\
\hline Range $(\mu \mathrm{g} / \mathrm{mL})$ & $4-40$ & $10-80$ \\
Slope & 71217 & 66761 \\
Intercept & 12015 & 8554.9 \\
Correlation coefficient & 0.9989 & 0.9995 \\
Retention time $(\mathrm{min}) *$ & $3.52 \pm 0.007$ & $8.03 \pm 0.003$ \\
$\mathrm{LOD}(\mu \mathrm{g} / \mathrm{mL})^{*}$ & $1.13 \pm 0.021$ & $1.37 \pm 0.029$ \\
$\mathrm{LOQ}(\mu \mathrm{g} / \mathrm{mL})^{*}$ & $3.43 \pm 0.037$ & $4.21 \pm 0.081$ \\
Recovery $(\mu \mathrm{g}) *$ & $98.51 \pm 0.59$ & $97.84 \pm 0.84$ \\
\hline
\end{tabular}

*Each mean value is the result of six analysis

Table II. System Suitability parameters

\begin{tabular}{lcccc}
\hline Parameters & Tamsulosin & \%RSD & Finasteride & \%RSD \\
\hline Retention time & 3.52 & 0.241 & 8.02 & 0.322 \\
Peak area & 2989418 & 0.632 & 4234810 & 0.12 \\
Theoretical plate & $6844 \pm 2$ & 0.069 & $11577 \pm 1.96$ & 1.24 \\
Tailing factor & $0.44 \pm 0.03$ & 0.065 & $0.82 \pm 0.04$ & 0.089 \\
\hline
\end{tabular}

Table III. Recovery Table

\begin{tabular}{|c|c|c|c|c|}
\hline Theoretical content $(\mu \mathrm{g} / \mathrm{mL})$ & Excess drug & Recovery $(\mu \mathrm{g} / \mathrm{mL})$ & \%Recovery & $\% \mathrm{RSD}$ \\
\hline \multicolumn{5}{|l|}{ Tamsulosin } \\
\hline 5 & 00 & 4.94 & 98.80 & 0.71 \\
\hline 7.5 & 2.5 & 7.45 & 99.33 & 1.29 \\
\hline 10 & 5 & 9.90 & 99.00 & 0.91 \\
\hline 12.5 & 7.5 & 12.53 & 100.24 & 1.02 \\
\hline \multicolumn{5}{|l|}{ Finasteride } \\
\hline 4 & 00 & 3.98 & 99.50 & 1.03 \\
\hline 6 & 2 & 5.96 & 99.33 & 0.67 \\
\hline 8 & 4 & 7.99 & 99.87 & 0.89 \\
\hline 12 & 8 & 12.04 & 100.33 & 1.71 \\
\hline
\end{tabular}

Table IV. Statistical Evaluation of Precision of developed method

\begin{tabular}{lcccccc}
\hline Compound & Concentration $(\boldsymbol{\mu g} / \mathbf{m L})$ & $\mathbf{n}$ & \multicolumn{2}{c}{ Interday-precision } & \multicolumn{2}{c}{ Intraday-precision } \\
\hline & & & Mean & RSD (\%) & Mean & RSD (\%) \\
\hline Tamsulosin & 5 & 5 & 04.82 & 0.750 & 05.02 & 0.316 \\
& 10 & & 09.84 & 0.278 & 14.06 & 0.743 \\
Finasteride & 15 & & 14.13 & 0.471 & 24.81 & 0.595 \\
& 15 & 5 & 14.12 & 0.563 & 09.87 & 0.804 \\
& 20 & & 19.13 & 0.838 & 18.94 & 0.933 \\
& 25 & 24.87 & 0.874 & 24.76 & 0.740 \\
\hline
\end{tabular}

$\%$ RSD of six replicate injections of TAM at LOD $(1.13 \mu \mathrm{g} / \mathrm{mL})$ and LOQ $(3.43 \mu \mathrm{g} / \mathrm{mL})$ were 1.85 and 1.07, respectively. Similarly \% RSD (relative standard deviation) of FIN at LOD $(1.37 \mu \mathrm{g} / \mathrm{mL})$ and LOQ $(4.21 \mu \mathrm{g} / \mathrm{mL})$ were 2.11 and 1.92 . These values indicated that method was very sensitive to quantify both drugs (Table I).

Robustness of method: In the robustness study, small deliberate variations in the optimized method parameters were done. The effect of change in mobile phase ratio, buffer 
Table V. Robustness study

\begin{tabular}{cccccc}
\hline \multirow{2}{*}{ Factor } & \multirow{2}{*}{ Level } & \multicolumn{2}{c}{ Retention time } & \multicolumn{2}{c}{ \% Recovery } \\
\cline { 3 - 5 } & & TAM & FIN & TAM & FIN \\
\hline \multirow{2}{*}{ Ratio of mobile phase } & $(75: 25 \mathrm{v} / \mathrm{v})$ & 3.12 & 8.08 & 100.2 & 100.1 \\
& $(65: 35 \mathrm{v} / \mathrm{v})$ & 3.79 & 7.83 & 99.8 & 100.3 \\
\multirow{2}{*}{ pH of mobile phase } & 3.3 & 3.44 & 7.91 & 100.1 & 100.2 \\
& 3.7 & 3.83 & 8.25 & 99.7 & 100.4 \\
Flow rate & $1.2(\mathrm{~mL})$ & 3.07 & 8.11 & 99.8 & 100.3 \\
& $0.8(\mathrm{~mL})$ & 3.72 & 8.17 & 100.1 & 99.8 \\
\hline
\end{tabular}

Table VI. Stability study

\begin{tabular}{cccccc}
\hline \multicolumn{2}{c}{ Short term stability } & \multicolumn{3}{c}{ Long term stability } \\
\hline Theoretical content & $\begin{array}{c}\text { Mean recovery } \\
\pm \text { SD }\end{array}$ & $\%$ RSD & $\begin{array}{c}\text { Theoretical } \\
\text { content }\end{array}$ & $\begin{array}{c}\text { Mean recovery } \\
\pm \text { SD }\end{array}$ & $\%$ RSD \\
\hline Tamsulosin & & & & & \\
\hline 4 & $102.18 \pm 2.32$ & 2.31 & 4 & $98.13 \pm 5.76$ & 5.98 \\
6 & $99.19 \pm 6.61$ & 6.60 & 6 & $97.34 \pm 5.23$ & 5.12 \\
8 & $100.79 \pm 4.63$ & 4.53 & 8 & $94.97 \pm 4.31$ & 4.45 \\
\hline Finasteride & & & & & \\
9 & $99.91 \pm 3.95$ & 3.89 & 6 & $97.55 \pm 5.26$ & 5.47 \\
12 & $98.82 \pm 5.39$ & 5.49 & 9 & $96.52 \pm 3.46$ & 3.68 \\
& $99.29 \pm 2.25$ & 2.23 & 12 & $96.47 \pm 3.64$ & 3.79 \\
\hline
\end{tabular}

$\mathrm{pH}$ and flow rate, on the retention time and $\%$ recovery were studied (table $\mathrm{V}$ ). The results showed that slight variations on the chromatographic conditions have negligible effect on the results showing that method was highly robust for its intended use.

Stability: Stability studies indicated that samples were stable when kept at bench top for $12 \mathrm{~h}$ (short-term), and refrigerated at $4^{\circ} \mathrm{C}$ for 30 days (long-term). Sample solution did not show any appreciable change in recovery value. The results of these stability studies are given in table VI, where the percent recoveries were within the acceptance range of $90-110 \%$.

Analysis of tablet: Tamsulosin and Finasteride tablets were evaluated for the amount of TAM and FIN present in the formulation. Each sample was analyzed in triplicate after extracting the drug as mentioned in the sample preparation of the experimental section. The amount of drugs present was $98.51 \%$ and $97.85 \%$, respectively for TAM and FIN. The reference chromatogram of standard pure drug (Figure 3) was matching with that of test sample chromatogram (drug extracted from the tablets) (Figure 4). The results are given in table I which shows high percentage recoveries and low RSD (\%) values.

\section{CONCLUSION}

The proposed method was simple, sensitive and reproducible and hence can be used for simultaneous determination of TAM and FIN in bulk as well as in tablet formulations. The statistical analysis of the results has been carried out revealing high accuracy and good precision. The \% RSD for all parameters was found to be low, which indicated that the method meet to the validity criteria. The assay results obtained by this method are in fair agreement. So, developed method can be used for routine quantitative simultaneous estimation of TAM and FIN in multicomponent pharmaceutical preparation.

\section{ACKNOWLEDGEMENTS}

The author are very grateful to School of Pharmacy KIET, Faculty of Pharmacy HRGI, and Faculty of Pharmacy Jamia Hamdard for supporting this research. 


\section{REFERENCES}

Amer SM., 2003, Polarographic behavior and determination of Finasteride, Farmaco, 58:159-63.

Basavaiah K., Somashekar BC., 2007, Determination of Finasteride in Tablets by HPLC Chromatography, E-J. of Chem., 4: 109-16.

Carlucci G., Mazzeo P., 1997. A HPLC method for the determination of Finasteride in human plasma, J. Chrom.. B Biomed. Sci. App, 693: 245-48.

Constanzer ML., Chavez CM., 1994. Picogram determination of finasteride in human plasma and semen by HPLC with atmospheric pressure chemicalionization tandem mass spectrometry, $J$. Chromat. 658: 281-87.

Constanzer ML., Chavbez CM., and Matuszewski BK., 1991. Determination of Finasteride in Human Plasma, J. Chromat. B. Biomed. App. 658: 281-87.

Din L., Li L., Tao P., Yang J., Zhang Z., 2002. Quantitation of tamsulosin in human plasma by liquid chromatographyelectrospray ionization mass spectrometry J. Chromatogr. B. 767: 75-81.

Guo FQ., Huang LF., Wong KP., Dai YH., Li YW., Liang YZ. Huang KL., Zhong KL., Wu MJ., 2007. A rapid, simple, specific liquid chromatographic- electrospray mass spectrometry method for the determination of finasteride in human plasma and its application to pharmacokinetic study, J. Pharm. Biomed. Anal. 43: 1507-13.

ICH: International Conference on Harmonization of Technical Requirements for Registration of Pharmaceuticals for Human Use, Validation of Analytical Procedures: Text and Methodology Q2 (R1), 2005.

Matsushima H., Takanuki KI., Kamimura H, Watanabe T., Higuchi S., 1997. Highly sensitive method for the determination of tamsulosin hydrochloride in human plasma dialysate, plasma and urine by HPLC-electrospray tandem mass spectrometry. J Chromat. B Biomed. Sci. Appl. 695: 317-27.
Patel DB., Patel NJ., 2010. Validated RP-HPLC and TLC methods for simultaneous estimation of tamsulosin hydrochloride and finasteride in combined dosage forms, Acta Pharm., 60: 197-05.

Ptacek P., Macek J., Klima DJ., 2000. Determination of finasteride in human plasma by liquid-liquid extraction and high-performance liquid chromatography, J. Chromat. 738: 305-10.

Rahkonen RP., Parssinen O., Leppanen E., Mauriala T., Lehtonen M., Auriola S., 2007. Determination of tamsulosin in human aqueous humor and serum by liquid chromatography-electrospray ionization tandem mass spectrometry, $J$. Pharm. Biomed. Anal. 43: 606-12.

Ramakrishna NV., Vishwottam KN., Manoj S., Koteshwara M., Wishu S., Varma, DP., 2005. Rapid, simple and highly sensitive LC-ESI-MS/MS method for the quantification of tamsulosin in human plasma, Biomed. Chromatogr., 19: 709-19.

Soeishi Y., Kobori M., Kobayashi S., Higuchi S., 1990. Sensitive method for the determination of tamsulosin in human plasma using high-performance liquid chromatography with fluorescence detection, J. Chromat. 533: 291-96.

Syed AA., Amshumali MK., 2001. LC determination of finasteride and its application to storage stability studies, $J$. Pharm. Biomed. Anal. 25: 1015-19.

The Merck Index, 14th ed., Merck Research Laboratories, Division of Merck \& Co., Inc., Whitehouse Station: New York, U.S.A., 2006; p1728.

Thimmaraju MK., Rao V., Gurrala S., 2011. RP HPLC method for the determination of finasteride and tamsulosin in bulk and pharmaceutical formulations, Der Pharm. Lett., 3: 79-86.

Xiaohong C., Erin RG., Douglas KP. and William DF., 2008. Development and validation of an LC-MS assay for finasteride and its application to prostate cancer prevention trial sample analysis, $J$. Chromat. Sci. 46: 356-6 